\title{
Influence of Moringa oleifera leaf extracts on germination and early seedling development of major cereals
}

\author{
C. Phiri \\ Department of Crop Science, University of Zambia, P.O. Box 32379, Lusaka, Zambia. \\ Author's e-mail: chris2phiri@yahoo.co.uk \\ ABSTRACT
}

\begin{abstract}
Germination and seedling growth of major cereals treated with Moringa oleifera leaf extracts was investigate at University of Zambia. Aqueous extract of Moringa oleifera at the ratio of 1:10 (w/v) were sprayed on seed of maize (Zea mays. L.), rice (Oryzae sativa.L.), sorghum (Sorghum bicolor. L.) and wheat (Triticum Aestivum. L.) in a growth room at $25^{\circ} \mathrm{C}$ for 14 days. The data were subjected to analysis of variance. $M$. oleifera leaf extracts enhanced $(p<0.04)$ germination of sorghum by $29 \%$, delayed $(p>0.05)$ germination of rice by $25 \%$ and reduced $(p>0.001)$ germination percentage of rice by $7 \%$. M. oleifera leaf extracts increased $(p<0.04)$ length of hypocotyls of wheat by $14.9 \%$, reduced $(p<0.03$ ) survival of sorghum seedlings by $15.3 \%$ and further reduced ( $p>0.001$ ) growth of hypocotyls by $42.9 \%$ in sorghum. $M$. oleifera increased $(p>0.001)$ radicle length of maize by $77.8 \%$ and reduced $(p<0.04)$ radicle length of rice by $28.6 \%$. Early contact of $M$. oleifera leaf extracts with seeds of cereals is undesirable. $M$. oleifera reduces radical length of rice, hypocotyls of sorghum, seedling survival of sorghum, germination percentage of rice and delays germination of rice.
\end{abstract}

Keywords: germination, cereals, Moringa oleifera, survival

\section{INTRODUCTION}

Maize, Wheat, Rice and Sorghum are the cereals of major economic importance in Zambia. Maize is the major staple food crop in Zambia supplemented by rice, wheat and sorghum. Production of cereal crops in Zambia has been beset with high cost of inorganic fertilizer and its erratic availability particularly to small scale farmers in remote areas. The dependency on use of inorganic fertilizer as a source of plant nutrients by farmers is further associated with land and soil degradation and environmental pollution. Other sources of plant nutrients such as prunings of Sesbania sesban, Leucaena leucocephala and Eucalyptus microtheca have been reported as possible alternatives to inorganic fertilizer (Hussein and Abbaro, 1997). However, these technologies take long to mature and are designed as single purpose technologies, mainly for soil fertility improvement. Plant extracts of some trees and crop residues have been reported to influence crop growth and yield (Farooq, et. al., 2008; Ahmed and Nimer, 2002; El Atta and Bashir, 1999; Chung and Miller, 1995; Guenzi, et. al., 1967). Leaf extracts of $M$. oleifera have been reported to accelerate growth of young plants, strengthen plants, improve resistance to pests and diseases, increase leaf area duration, increase number of roots, produce more and larger fruits and generally increase yield by 20 to $35 \%$ (Fuglie, 2000).
$M$. oleifera is increasingly becoming popular among communities in Zambia for use as a food supplement, weaning food in children and for medicinal purposes. Stakeholders such as the health sector promote $M$. oleifera as a food supplement while others such as the water sector promote $M$. oleifera for water treatment purposes. The use of $M$. oleifera for agricultural purposes to enhance growth and yield of crops has not been investigated in Zambia.

In the wake of skyrocketing global prices of inorganic fertilizer, the land and water pollution associated with use of inorganic fertilizer and the contribution of inorganic fertilizer to climate change, there is a need to search for alternative sources of plant nutrients. $M$. oleifera is one such alternative being investigated to ascertain its effect on growth and yield of crops so that $M$. oleifera can be promoted as a possible supplement or substitute to inorganic fertilizer and be promoted as a multipurpose plant among farmers. The objective of this study was to investigate the effect of $M$. oleifera leaf extracts on germination and early seedling growth of four major cereals; maize, wheat, sorghum and rice in Zambia.

\section{MATERIALS AND METHODS}

The study was carried-out at University of Zambia located $15^{\circ} 23^{\prime} S$ and $28^{\circ} 20^{\prime} E$ during 2009 to test the effect of Moringa oleifera leaf extracts on germination and early seedling growth of major cereals; maize 
(Zea mays. L.), rice (Oryzae sativa.L.), sorghum (Sorghum bicolor. L.) and wheat (Triticum Aestivum. L.). Aqueous extract of $M$. oleifera at the ratio of $1: 10$ $(\mathrm{w} / \mathrm{v})$ was prepared by mixing $30 \mathrm{~g}$ of plant leaf material with $300 \mathrm{ml}$ of distilled water in a household blender for 15 minutes. The solution was filtered through filter paper, Whatman No. 42. Petri dishes were sterilized for 1 hour 30 minutes in an autoclave. Ten (10) seeds of maize and similar quantities of wheat, rice and sorghum were placed at the bottom in separate petri dishes and covered with filter paper, Whatman No. 2. The treatments were arranged in a completely randomized design with three replicates. $M$. oleifera leaf extracts were applied twice to each petri dish during the study. The first application of $M$. oleifera leaf extracts was done at beginning of experiment. This was followed by the second application of $M$. oleifera leaf extracts done on day 7 of the experiment. Distilled water was used as a control. Petri dishes were incubated in a growth room at $25^{\circ} \mathrm{C}$ for 14 days.

Measurements recorded were duration to germination, germination percentage, radicle and hypocotyl lengths and percent seedling survival. Duration to germination was recorded when at least $50 \%$ germination of seeds in each petri-dish was recorded. Germination percentage was recorded at $24 \mathrm{~h}$ interval for 14 days, when it was apparent that seed germination had come to an end. Radicle and hypocotyl lengths and seedling survival were recorded on day 14 at end of the study.

Data Analysis: Data were analyzed following analysis of variance (Genstat, 2008) procedure. Treatment means were separated using least significant difference (Little and Hills, 1978).

\section{RESULTS AND DISCUSSION}

Duration to germination: Results presented in Figure 1 show that Moringa oleifera leaf extracts reduced $(p \leq 0.001)$ duration to germination of sorghum by $29 \%$ increased duration to germination of rice by $25 \%$. However, $M$. oleifera leaf extracts did not affect duration to germination of maize and wheat. The experiment indicated that $M$. oleifera leaf extracts is desirable in sorghum to enhance germination, but undesirable in wheat because it delays germination. The enhanced germination of sorghum has the practical significance of early germination of sorghum leading to early ground cover and increased duration for growth of sorghum. The delayed germination of wheat has practical implications of delayed establishment and comparatively shorter duration for growth of wheat.

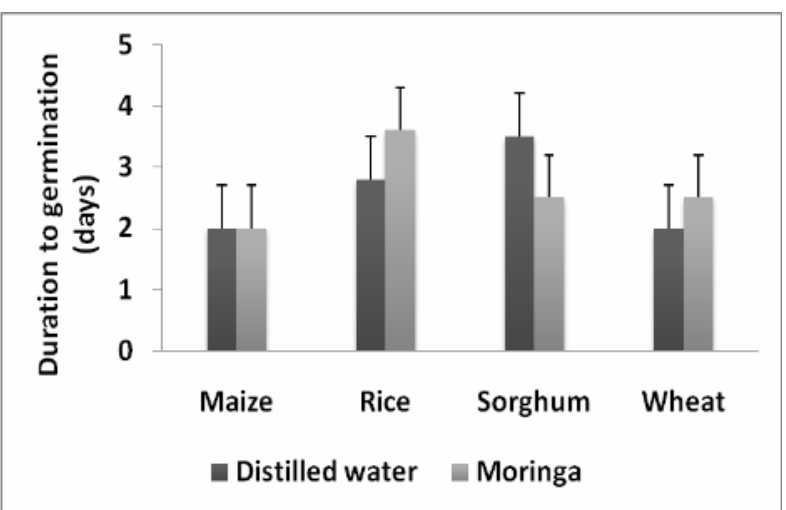

Fig 1. Duration to germination of maize, rice, wheat and sorghum treated with $M$. oleifera leaf extracts at University of Zambia

(Error bars are standard errors of means)

Percent germination: Results in Figure 2 show that $M$. oleifera leaf extracts reduced $(p<0.001)$ germination percentage of rice by $7 \%$, but did not affect percent germination of wheat, maize and sorghum. The results of reduced germination percentage in rice and non significant effect on germination of other cereals are not consistent with the findings of Foidl et al (2001) who reported a general improved crop performance in response to application of leaf extracts of Moringa oleifera. The results of this study showed that $M$. oleifera leaf extracts contained substances with inhibitory effect (Sanker and Rai, 1993; Zakaria and Razak, 1990) which could have lowered germination percentage of rice. However, the inhibitory substances were not isolated in this study. The differences in the germination percentage of rice and the other cereals could be attributed to differences in the selective permeability of the seed coat of sorghum, maize, wheat and rice to inhibitory substances (Zakaria and Razak, 1990) and inhibitory growth substances in some crops which could have lowered germination percentage of rice (Wicks, et al., 1994.).

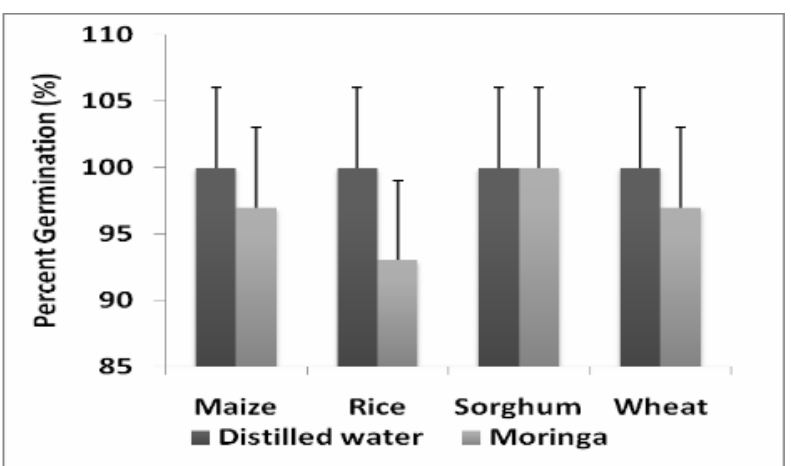

Fig 2. Germination of maize, rice, wheat and sorghum treated with $M$. oleifera leaf extracts at University of Zambia (Error bars are standard errors of means) 
Seedling survival: $M$. oleifera leaf extracts reduced $(p<0.001)$ survival of sorghum seedlings by $15.3 \%$, but did not affect survival of other seedlings (Figure 3 ). The results indicate that sorghum is more sensitive to $M$. oleifera leaf extracts compared to other cereals. The results also show that extracts from fresh leaves of $M$. oleifera contain substances with inhibitory substances (Sanker and Rai, 1993; Zakaria and Razak, 1990) which could have lowered seedling survival of sorghum.

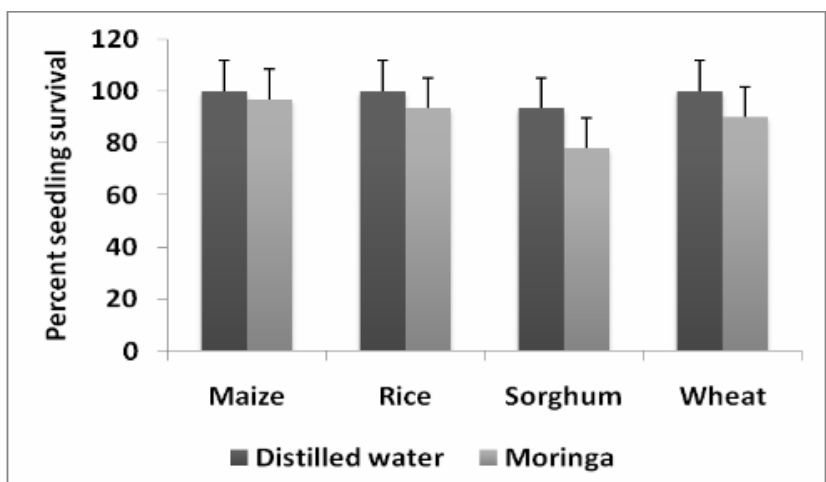

Fig 3. Seedling survival of maize, rice, wheat and sorghum treated with $M$. oleifera leaf extracts at University of Zambia

(Error bars are standard errors of means)

Hypocotyl length: Application of $M$. oleifera leaf extracts increased $(P<0.04)$ growth of hypocotyls of wheat by $14.9 \%$. Application of $M$. oleifera leaf extracts had the opposite effect of reducing $(P<0.04)$ growth of hypocotyls of sorghum by $42.9 \%$ (Figure 4 ). The results obtained in wheat of increasing hypocotyl length recorded in wheat are in agreement with the findings of Foidl et al (2001) who reported an improved crop performance in response to application of $M$. oleifera leaf extracts. The results of longer hypocotyl lengths obtained in wheat in this study have positive implications of early emergence and establishment of crops, an important factor to obtain early establishment and crop ground cover.

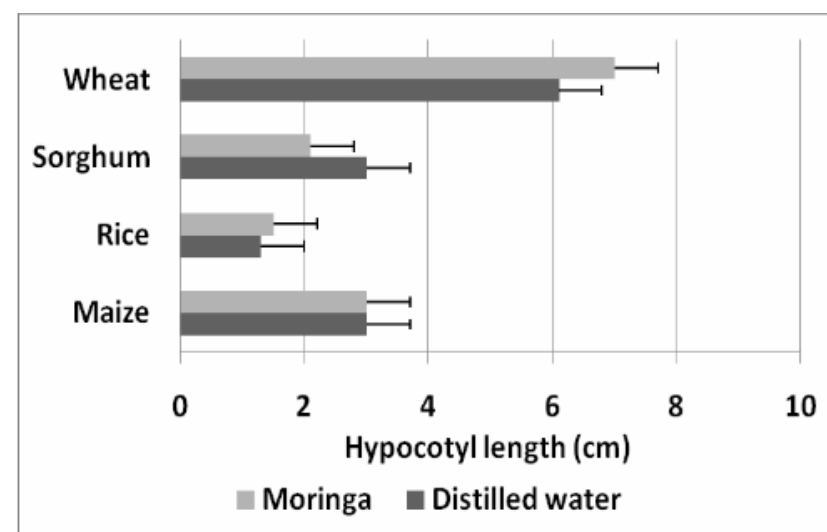

Fig 4. Comparative growth (cm) of hypocotyls of maize, wheat, rice and sorghum treated with $M$. oleifera leaf extracts at University of Zambia

(Error bars are standard errors of means)

Radicle length: Results of radicle length presented in Figure 5 show that $M$. oleifera leaf extracts increased $(P \leq 0.001)$ radicle length of maize by almost double $(77.8 \%)$ that recorded in the control. The increase in radicle length of maize arising from application of $M$. oleifera leaf extracts has positive implications of increased root length and improved survival of maize seedlings during periods of drought. $M$. oleifera leaf extracts reduced radicle length of rice by $28.6 \%$. However, M. oleifera leaf extracts had no effect on radicle lengths of sorghum and wheat. The reduced radicle lengths recorded in rice have negative implications of reduced root length and lower field survival of rice under water stress conditions. The results of reduced radicle length recorded in rice and the non significant effect of $M$. oleifera on radicle length of wheat and sorghum are in agreement with the findings of Phiri and Mbewe (2009) of reduced radicle length and delayed germination of common beans treated with $M$. oleifera leaf extracts. However, these results are not consistent with the results reported by Foidl et al (2001) of general improved crop performance when applied with $M$. oleifera leaf extracts. The variations in the results obtained could be attributed to the direct contact between seed and $M$. oleifera leaf extracts which could have led to impaired development of radicles of rice. 


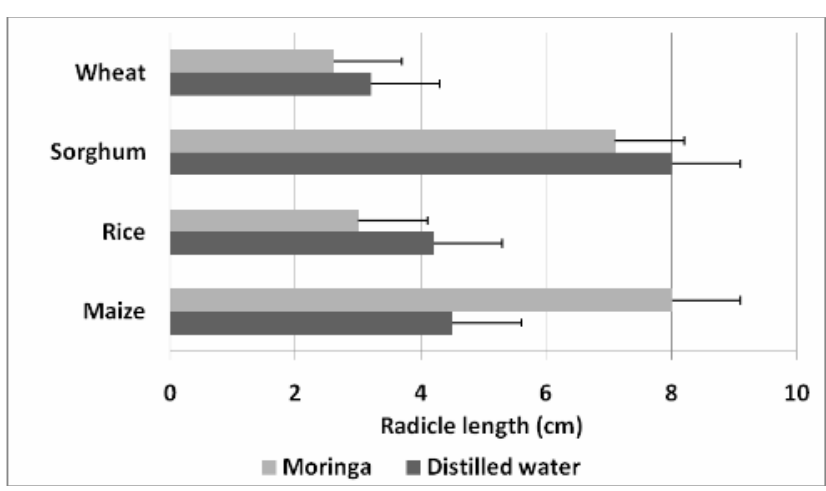

Fig 5. Comparative growth $(\mathrm{cm})$ of radicles of maize, wheat, rice and sorghum treated with $M$. oleifera leaf extracts at University of Zambia (Error bars are standard errors of means)

\section{CONCLUSION}

Early contact of $M$. oleifera leaf extracts with seeds of cereals enhanced germination of sorghum, length of maize radicals and hypocotyls of wheat. However $M$. oleifera leaf extracts have undesirable effects of reducing radicals of rice, hypocotyls of sorghum, seedling survival of sorghum, germination percentage of rice and delaying germination of rice which is likely to delay germination, reduce establishment and reduce field survival of cereals.

\section{ACKNOWLEDGEMENT}

The author would like to thank Mr Japhet Phiri, Assistant Technician in Department of Crop Science at University of Zambia for collecting data for this study.

\section{REFERENCES}

Ahmed, D.M. and Nimer, A.M (2002). Effects of Acacia senegal (L., Wild) on sandy soils. A case study of El Damokya Forest, Northern Kordofan State. Univ. Khartoum J. Agric. Sci., 10: 106-118

Chung, M. and Miller, D.A (1995). Allelophathic influence of nine forage grasses on germination and seedling growth of alfalfa. Agron. J., 87: 767-782

El Atta, H.A. and Bashir, I.A (1999). Adverse effects of Eucalyptus camaldulensis (Dehn) leaf extract on germination and seedling growth of wheat. University Khartoum J. Agric. Sci., 7: 70-79
Farooq, M., Jabran, K., Rehman, H. and Hussain, M (2008). Allelopathic effects of rice on seedling development in wheat, oat, barley and berseem. Allelopath. J., 22: 385-390

Foidl, N., Makkar, H.P.S. and Becker, K (2001). The potential of Moringa oleifera for agricultural and industrial uses, pp 45-76, In: The Miracle Tree: The Multiple Attributes of Moringa (Ed) Lowell J. Fuglie, CTA, Wageningen, The Netherlands

Fuglie, L.J (2000). The Miracle Tree: Moringa oleifera: Natural Nutrition for the Tropics. The Miracle Tree: The Multiple Attributes of Moringa, pp 172

Genstat (2008). Discovery edition 3. VSN International Ltd. 5 The waterhouse, waterhouse street, Hemel Hempstead, HP1 1ES, UK

Guenzi, W. D., McCalla T.M. and Norstadt, F.A (1967). Presence and persistence of phytotoxic substances in wheat, oat, corn and sorghum residues. Agron. J., 59: 163-165

Hall, A. B., Blum, U. and Fites, R.C (1982). Stress modification of allelopathy of Helianthus annuus L. debris on seed germination. American J. Bot., 69: 776783

Hussein, S.G. and Abbaro, M.B (1997). The influence of prunings of Leucaena leucocephala and Eucalyptus microtheca used as green manure mulch on growth and yield of fodder sorghum (Sorghum bicolor L.). University of Khartoum J. Agric. Sci., 5: 106-114

Little, T.M and Hills, F.J (1978). Agricultural experimentation. Design and analysis. John Willey and sons, New York. pp 350

Phiri, C. and Mbewe, D. N (2009). Influence of Moringa oleifera leaf extracts on germination and seedling survival of three common legumes. International Journal of Agriculture and Biology (in Press)

Sanker, K.B. and Rai, R.S.V (1993). Allelopathic effects of a few tropical hardwoods on olericultural crops. Indian J. Fores., 16: 246-249

Wicks, G.A., Crutchfield, D.A. and Burnside, O.C (1994). Influence of wheat (Triticum aestivum) straw mulch and metolachlor on corn (Zea mays) growth and yield. Weed Sci., 42: 141-147

Zakaria, W. and Razak, A.R (1990). Effects of groundnut plant residues on germination and radicle elongation of four crop species. Pertanika, 13: 297-302 